Volume 8, Number 1, June 2020

pp. $332-339$

\title{
Semiotic Analysis in Instagram Logo
}

\author{
Eva Eriva Tandi Payuk ${ }^{1}$ Zakrimal $^{2}$ \\ evaerivatp@gmail.com \\ 1, 2.English Department, Putera Batam University
}

Received: 9 June 2020 Accepted: 30 June 2020

DOI: 10.24256/ideas.v8i1.1383

\begin{abstract}
This article investigated about semiotic that found in instagram logo. This article used Instagram, because many people nowadays used Instagram to express their selves. The aim of this study was to find out the connotative and denotative meaning through the instagram. The researcher used John theory to reveal this study. In this research, the researcher applied the qualitative descriptive method. The method of collecting data was observation. The object of this research was the instagram logo. The result is there are twelve data that has meaning from different logo on Instagram. They all have different functions based on the logo. The conclusion is Instagram as a social media app that allows users to share photos and videos, add captions, edit filters, engage with others, and explore the world by using this application.
\end{abstract}

Keywords: Semantics, semiotic, instagram 


\section{Introduction}

Social media is the tool that people need now, it could be facebook, instagram, whatsapp, twitter and others. As usual the emerge of social media has a multiple platform. One of the social media is Instagram. Instagram is a photo and video sharing application that allows users to take photos, take videos, use digital filters, and other networking activities. Continue to increase Instagram is not far from the role of special features that is offered by Instagram. Instagram is a social media that allows users to share photos and videos with their followers.

Features in instagram must use persuasive sentences, phrases or jargon or in other words, trying to seduce the general public into interact people to use the application. The logo must be that interesting, easy to remember, and easy to understand for all people. Nowadays people in doing business are trying to make people is interested by the sign that created as creative as they can. But people must to know what the meaning in the logo is. For example the picture fire in LPG means that it is easy to be burnt. Everybody could determine their meaning based on the symbol or sign itself.

A study that explains about sign called as semiotics. Lyons \& John (1995) says that semantics is the study of meaning. The term of meaning in the theory of semantics can be described from the mind of speaker to the mind of hearer by embodying them, as it was, in the form of one language or another. Everything that can be seen or observed can be called a sign. Something in question can be ideas, thoughts, experiences (something experienced) or feelings, signs are not limited to objects. If $A$ is known and is known to represent $B$, then $A$ is a sign. $A$ is a red traffic light, motorists should not cross the road; B. Signs can be divided into three categories, namely icons, symbols and indexes.

There are two previous researches that have relation to this study. The first is Sukyadi, Setyarini, \& Junida (2011) with the title a semiotic analysis of cyber emoticons (a case study of Kaskus emoticons in the lounge forum at Kaskus-the largest Indonesian Community). They explored the significance of Kaskus emoticons in the Lounge forum at Kaskus, the Largest Indonesian Community. This analysis is rooted on semiotics, particularly Roland Barthes'orders of signification involving five emoticons appearing in the Lounge forum at the site. The findings show that the emoticons have meaning and functions as a way to communicate, particularly in the online forum.

Prasojowati, Natsir, and Ariani (2019) with the title a semiotic analysis found on the cigarette products. The writer used some expert theories like Bouzida, Cuppens, Cuppens-Boulahia, \& Gombault, (2004), Zapilko, Schaible, Mayr, \& Mathiak, (2013) They wanted to show that the messages or the semiotic signs found on cigarette product was conveyed successfully by the active smoker or the viewer, where the active smoker means a person who have been actively smoke since specific long time, here in this study.

This research is important to analyze because in a broader sense, the theory of 
semiotics are important to a systematic study of the production and interpretation of signs, how they work and how they benefit human life. Humans are sign creatures, in their lives are filled with signs, because through intermediaries the signs of humans can communicate with each other. That is why the researcher is interested to analyze semiotics under the title "Semantic Analysis in Instagram Logo".

According to Steyvers (2006) semantics is one of the two main branches of linguistic studies. Basically, it is the study of meaning. He defines semantics as the study of word meaning and sentence meaning; it differs from pragmatics which relates language and its contexts. A semantic theory is interested in sentence meaning and not speaker meaning. The difference semantics and pragmatics. Extremely, he states that pragmatics, which concerns on speaker's intention, also has contribution in determining semantic content. Bach in Carston (2008) adds that there are two kinds of context: narrow and broad. The narrow belongs to semantics and the broad belongs to pragmatics.

In his book about pragmatics, Yule (2016) differentiates the term semantics, syntax and also pragmatics. He stated that syntax is about the relationships between linguistic forms and how it is arranged and formed. Then, pragmatics is about the 13 relationship between linguistic forms and its users. The last, the relationship between linguistic forms and the real things in the world which the linguistic forms refer to is called as semantics. Semantics questions how words literally relate to things, not to the users or contexts.

Related to the discussion of semantics and grammar, John (1995) explains Katz and Fodor"s slogan of semantics which says, "Linguistic description minus grammar equals semantics." In this case, the discussion of grammar covers syntax, morphology and phonology. In conclusion, semantics explains the speaker"s ability in understanding new words or sentences without any grammatical processes.

Under the study of semantics, some topics are discussed. Some are semantic features, semantic roles and semantic relations. Yule explains that semantic features are the elements with the sign of plus $(+)$ or minus $(-)$ to differentiate words meanings in a language. Then, a part played by a noun phrase in a sentence is called as a semantic role.

Signification is process that connects the meaner and the sense of the sign. Two signifying systems exist: arbitrary and motivated. Arbitrary meaning means that the unilateral decision makes the relationship between signifier and signified. In other words, arbitrary means no natural relationship exists between a word and the object to which it refers.

The signification is divided into two steps: first order of signification and second order of signification. The first order of signification describes the relationship between the signifier and signified of a sign. Barthes calls the first order of signification "denotation", which refers to the obvious meaning of the sign. Since Barthes is Saussure's follower, their concepts of signifier and signified writing. For example, the image of a white-gray uniform is a signifier of a 
highschool- student uniform.

\section{Method}

This article used Sudaryanto (1993) qualitative descriptive data provide a verbal description of human activities and the concerns more on the representative sample as the main data. It was very suitable with this research because this study is describing the analyzing of Instagram, so qualitative descriptive is agree to description and concern more on the representative of the data. This study was descriptive because the writer become the main instrument data, describing data and analyzing the finding to answer the problem of the study

The writer took Instagram as the text because this Instagram considered to have many interesting parts to analyzed, as we know in Instagram logo. There were some steps to collect the data in this research:

a. The writer collected the data by capturing the data in instagram official logo.

b. After the writer got the pictures of the data, as the population of data analysis. The writer classified the data which were needed to be described.

c. The last, the writer analyzing the data used semiotics theory to find out the connotation and denotation meaning in Instagram.

\section{Results and Discussion}

Data 1

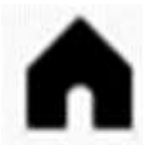

The symbol in the above means Feeds on Instagram, it function is for the user to know what their follower or their friends doing in instragam. Usually it can be a moment like a picture or video. The logo itself look like a house with the black color in the app and it have the meaning home, family, and friend. The instagram use this symbol to make their user understand without a letter.

Data 2

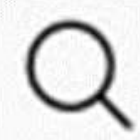

The symbol above means search on instagram. It function is for the user search someone, picture, video, or anything that in instagram. The logo itself is look like magnifying glass that can be meaning to find or searching something. It can be instagram use magnifying glass as the symbol for the symbol search is acceptable. The instagram use this symbol to make their user understand without a letter. 
Data 3

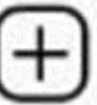

The symbol above means upload in instagram. It function is for the user to upload some their moment such as picture or video. When user wants to upload their picture, first pick the picture then the user can put filter and edit their photo lastly they can put caption or comment in their picture. The symbol itself look like rectangle with plus in the middle. This can be mean add something to gallery. Or add something in the store. The instagram use this symbol to make their user understand without a letter.

Data 4

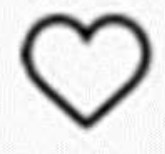

The symbol above means love and activity. There are some functions for it. The first is for the user to react to the picture means he or she like the feeds or the picture. And another function is for the user to check their activity in their instagram. The logo or symbol look like the picture of heart that can be means something lovely or like someone or healthy. The instagram use this symbol to make their user understand without a letter.

\section{Data 5}

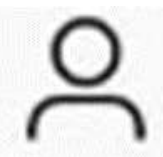

The symbol above means profile in the instagram. It function is for the user check their profile. It contain biodata, username, the old picture that has been uploaded. The user can also check their story or snap gram in the profile. The symbol itself look like a person and it can be mean user identity. The instagram use this symbol to make their user understand without a letter.

Data 6

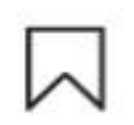

The symbol in the above means to save some photos or videos on Instagram, it function is for the user to be easy to find what they like before without searching it 
again. Usually it can be a moment like a picture or video. The logo itself look like square but it had been cut below and divided into two with a black color in the app and it have the meaning and located after the photos or videos.

\section{Data 7}

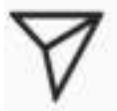

The symbol above has meaning to message or it is known as direct message on instagram. So, if people want to ask or inform something privacy, it can use this logo. There are some functions for it. The first is for the user to contact more privacy between two people because if it used comment, people could see that. To know that people sometimes mentioned them in their story. The logo or symbol looked like the picture of arrow that can be means something that is directly forward to send. The instagram used this symbol to make their user understand without a letter.

Data 8

\section{IGTV}

The symbol above means in istagram has tv logo to save longer video that upload it in the feed. It has a function to upload and express the long video by using IG TV. The symbol itself, it looks like a TV picture but there was a wave line inside the TV. It has black colour inside the TV logo

Data 9:

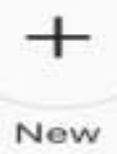

The symbol above means upload in story instagram. It function is for the user to upload some their moment such as picture or video but it did not take a long time, it was only 24 hours. When user wants to upload their picture, first pick the picture then the user can put filter and edit their photo lastly they can put caption or comment in their picture. The symbol itself look like rectangle with plus in the middle. This can be mean add something to gallery. Or add something in the store. The instagram use this symbol to make their user understand without a letter. 
Data 10:

This symbol means boomerang. The function is to take a burst of photos and stitches them together into a high-quality mini video that plays forward and backward. It function is for the user took picture, video, or anything that in instagram. The logo itself is look like disconnecting circle It can be used when people wanted to vary their style of photo. The instagram used this symbol to make their user understand without a letter.

Data 11:

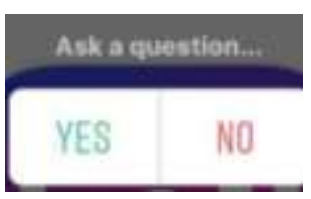

The symbol above means asking question because they wanted to ask something to convince their selves in uploading something or not. It is used because people sometimes does not believe their selves. The symbol itself looks like the question and the answer, there is no or yes answer. This can be meant ask adding something to gallery. Or add something in the store. The instagram used this symbol to make their user understand without a letter.

After analyzing the data, the research found some findings. There are 11 data that researcher collected from the instagram. There are all have different meaning from the semiotic itself. If we look all the data above, all the logo on instagram have their own rule and function.

\section{Conclusion}

From all the research analysis and finding, the researcher conclude that, the logo or symbol used in instagram is compatible with their function. The meaning of the logo or symbol itself almost same with the denotation and connotation meaning. The logo itself really helpful and really mirroring their meaning. With little information like logo the user can operate the instagram without written explanation about the logo 


\section{References}

Carston, R. (2008). Linguistic communication and the semantics/pragmatics distinction. Synthese, 165(3), 321-345.

Grice, H. P. (1972). Intention and uncertainty. New York: Oxford University Press.

Lyons, J., \& John, L. (1995). Linguistic semantics: An introduction. Cambridge University Press.

Masruddin, M. (2018). The Importance of Using Technology in English Teaching and Learning. IDEAS: Journal on English Language Teaching and Learning, Linguistics and Literature, 2(2). doi:https://doi.org/10.24256/ideas.v2i2.36

Munawir, A. (2019). Online Game and Children's Language Behavior. IDEAS: Journal on English Language Teaching and Learning, Linguistics and Literature, 7(2). doi:https://doi.org/10.24256/ideas.v7i2.1050

Prasojowati, M. W., Natsir, M., Ariani, S., \& Literature, E. (2019). A semiotic analysis found on the cigarette products. Ilmu Budaya, 3(1), 86-91.

Steyvers, M., Griffiths, T. L., \& Dennis, S. (2006). Probabilistic inference in human semantic memory. Trends in Cognitive Sciences, 10(7), 327-334.

Sudaryanto. (1993). Method dan teknik analysis bahasa. Yogyakarta: Duta Wacana University Press.

Sukyadi, D., Setyarini, S., \& Junida, A. I. (2011). A Semiotic Analysis of Cyber Emoticons (A Case Study of Kaskus Emoticons in the Lounge Forum at Kaskus-the Largest Indonesian Community). K@Ta, 13(1), 37-50. https://doi.org/10.9744/kata.13.1.37-50

Thomas, J. (1995). Learning about language meaning in interaction. United Kingdom: Cambridge University Press.

Yule, G. (2016). The study of language. Cambridge university press. 